\title{
Factors predicting recurrence after curative resection for rectal cancer: a 16-year study
}

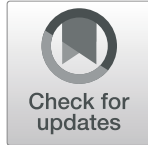

\author{
Waad Farhat', Mohamed Azzaza', Abdelkader Mizouni ${ }^{1}$, Houssem Ammar ${ }^{1 *} \mathbb{D}$, Mahdi ben Ltaifa ${ }^{1}$, Sami Lagha', \\ Mohamed Kahloul' ${ }^{2}$ Rahul Gupta ${ }^{3}$, Mohamed Ben Mabrouk ${ }^{1}$ and Ali Ben Ali ${ }^{1}$
}

\begin{abstract}
Background: The recurrence after curative surgery of the rectal adenocarcinoma is a serious complication, considered as a failure of the therapeutic strategy. The aim of this study was to identify the different prognostic factors affecting the recurrence of adenocarcinoma of the rectum.
\end{abstract}

Methods: A retrospective analysis of patients operated for adenocarcinoma of the rectum between January 2000 and December 2015 was conducted. The study of the recurrence rate and prognostic factors was performed through the Kaplan Meier survival curve and the Cox regression analysis.

Results: During the study period, 188 patients underwent curative surgery for rectal adenocarcinoma, among which 53 had a recurrence. The recurrence rate was $44.6 \%$ at 5 years. The multivariate analysis identified four parameters independently associated with the risk of recurrence after curative surgery: a distal margin $\leq 2 \mathrm{~cm}$ $(H R=6.8,95 \% \mathrm{Cl} 2.7-16.6,6)$, extracapsular invasion of lymph node metastasis ( $\mathrm{HR}=4.4,95 \% \mathrm{Cl} 1.3-14)$, tumor stenosis ( $H R=4.3,95 \% \mathrm{Cl} 1.2-15.2)$, and parietal invasion (pT3/T4 disease) ( $H R=3,95 \% \mathrm{Cl} 1.1-9.4)$.

Conclusion: The determination of the prognostic factors affecting the recurrence of rectal adenocarcinoma after curative surgery allows us to define the high-risk patients for recurrence.

Trial registration: ClinicalTrials.gov Identifier: NCT03899870. Registered on 2 February 2019, retrospectively registered.

Keywords: Rectal adenocarcinoma, Recurrence, Prognosis

\section{Introduction}

Colorectal cancer is one of the most frequently diagnosed cancers and a major cause of cancer deaths worldwide [1]. Recurrence after curative surgery is one of the major factors affecting the long-term survival and its frequency is estimated to be $22.5 \%$ at 5 years, of which $12 \%$ have a local recurrence. The overall survival in case of recurrence is about $11 \%$ at 5 years [2]. Several patient-, tumor-, and treatmentrelated prognostic factors are associated with the risk of recurrence of rectal adenocarcinoma. Some of these factors such as TNM stage [3], lymphatic and perineural invasion $[3,4]$, and vascular emboli $[5,6]$ have been found to affect recurrence-free survival in most studies. While the impact

\footnotetext{
* Correspondence: hosshoss24@hotmail.fr

'Department of Gastrointestinal Surgery, Sahloul Hospital, Sousse, Tunisia

Full list of author information is available at the end of the article
}

of other factors such as distal resection margin [7], tumor size $[8,9]$, extracapsular spread [10], and neoadjuvant chemoradiotherapy $[11,12]$ on recurrence remains controversial. Most of the previous studies on prognostic factors have been from American and European countries with very little data from African countries. Recognition of these factors helps in the identification of high-risk patients who require close and more rigorous postoperative surveillance. Hence, this study was conducted to determine the factors affecting recurrence after curative resection of rectal cancer in the African population.

\section{Patients and methods}

This is a retrospective study of prospectively maintained data of all the patients who underwent curative resection for rectal adenocarcinoma over 16 years (between January 2000 and December 2015) at the Department of Digestive and Visceral Surgery of Sahloul Hospital, Sousse, Tunisia.

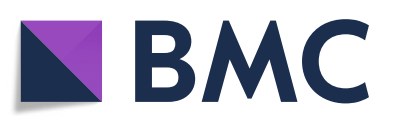

(c) The Author(s). 2019 Open Access This article is distributed under the terms of the Creative Commons Attribution 4.0 International License (http://creativecommons.org/licenses/by/4.0/), which permits unrestricted use, distribution, and reproduction in any medium, provided you give appropriate credit to the original author(s) and the source, provide a link to the Creative Commons license, and indicate if changes were made. The Creative Commons Public Domain Dedication waiver (http://creativecommons.org/publicdomain/zero/1.0/) applies to the data made available in this article, unless otherwise stated. 
We excluded patients who underwent palliative surgery, patients with microscopically or macroscopically positive resection margin (proximal, distal, or circumferential), patients with tumors other than adenocarcinoma, and those who died in the postoperative period because of complications. Informed consent was taken from all patients. This study was approved by the research ethics board of Sahloul Hospital and has been performed in accordance with the ethical standards laid down in the 1964 Declaration of Helsinki and its later amendments.

\section{Preoperative staging}

1. T staging - On MRI pelvis, tumor extending into the perirectal fat was labeled as T3 disease and those invading adjacent organs were considered to have T4 disease [13].

2. Nodal staging-On MRI pelvis, heterogeneity of signal intensity on T2W sequences or irregular margins of the lymph nodes or lymph node size $>8$ $\mathrm{mm}$ was considered to be pathological [13].

\section{Neoadjuvant therapy}

Patients with locally advanced disease (cT3, cT4) or lymph nodal positive disease were offered neoadjuvant therapy. In the neoadjuvant therapy, we used $45 \mathrm{~Gy}$ in 25 fractions with concurrent 5-fluorouracil [5-FU] infusion $\left(600 \mathrm{mg} / \mathrm{m}^{2}\right)$ [14]. Patients were operated 8 to 10 weeks after neoadjuvant therapy $[15,16]$. Sometimes, for the elderly patients with multiple co-morbidities, we used short-course pelvic radiation therapy which included 25 Gy in five fractions over 1 week.

\section{Surgery}

Patients with tumors in the upper and middle third rectum underwent anterior and low anterior resection, respectively. Patients with tumors in the lower third of the rectum where anal sphincters could not be preserved underwent abdominoperineal resection. In most of the cases, inferior mesenteric artery (IMA) was ligated caudal to the origin of the left colic artery to preserve the autonomic nerves at the IMA origin and maintain a good blood supply to the left colon and the anastomotic site. For the tumors of the upper rectum, partial excision of the mesorectum was performed up to a minimum of $5 \mathrm{~cm}$ from the inferior aspect of the tumor. For the tumors of the middle and low rectum, a total mesorectum excision was done with the minimum distal mucosal margin of 1 to $2 \mathrm{~cm}$. In cases where coloanal anastomosis was performed, an ileostomy was made. However, after low colorectal anastomosis, an ileostomy was performed if the colon was poorly prepared or the anastomotic leak test was positive.
In most of the cases, open surgery was performed. Laparoscopic surgery was performed in selected cases. Wide local excision was performed in selected cases with T1 tumors without locoregional lymphadenopathy.

\section{Adjuvant therapy}

Patients with locally advanced disease (pT3, T4) or lymph nodal positive disease were offered adjuvant therapy. In most of the cases, FOLFOX (leucovorin, 5-FU, oxaliplatin) regimen was used and for elderly patients who could not tolerate this regimen, we used oral capecitabine.

\section{Follow-up}

Postoperative follow-up included clinical examination, serum carcinoembryonic antigen (CEA) levels, and abdominal ultrasound every 3 months during the first 2 years and then every 6 months for 2 years. We also performed a thoraco-abdominopelvic CT scan every 6 months for the first 2 years and then every year for 3 years. Colonoscopy was done after 1 year, and if it was normal, it was repeated after 3 years.

\section{Definitions}

Adenocarcinoma of the rectum was defined as cancer arising from the glandular cells of the rectal epithelium and located anatomically within the last $15 \mathrm{~cm}$ of the digestive tract from the anal canal.

Recurrence was defined as the development of any new malignant lesion within the field of surgery (locoregional recurrence) or outside it (distant metastasis) after initial resection was judged to be curative (R0) based on the preoperative imaging and histopathological examination of the resected specimen. The confirmation of the recurrence was made by pathological examination of a biopsy performed during an endoscopic examination, a laparotomy, computed tomography-guided biopsy, or finally at autopsy.

\section{Statistical analysis}

The qualitative variables were summarized by simple and relative frequencies. Quantitative variables were expressed as the median and interquartile interval. The frequency of recurrence of rectal adenocarcinoma was calculated by the incidence density and using the Kaplan-Meier survival analysis. All the variables associated with recurrence with $p<0.20$ on univariate analysis were integrated into a Cox regression model that allowed the identification of prognostic factors independently associated with recurrence by calculating the hazard ratio (HR) with their 95\% confidence intervals. The mean and median time to recurrence was calculated using the Kaplan-Meier curve. The log-rank test was used to compare the Kaplan-Meier curves for the 
prognostic factors independently associated with rectal adenocarcinoma recurrence.

\section{Results}

During the study period, 269 patients were operated for rectal adenocarcinoma. Out of these, 188 patients were included in this study. Fifty-three patients developed recurrence in the follow-up period. The basic characteristics of the study population were summarized in Table 1. The sex ratio was 1.35 and the mean age was 60.5 years $(50-71.7)$ for the total population versus a sex ratio of 0.8 and a median age of 60 years (45.5-70) for patients who had a recurrence.

The median recurrence-free survival was 54 months. The recurrence rate was $44.6 \%$ at 5 years and $58.4 \%$ at 10 years (Fig. 1). The incidence density of recurrence was $1 / 10$ patient-year.

The recurrence rate was $17 \%$ (9 cases) for tumors of the upper rectum versus 30\% (16 cases) for tumors of the middle rectum and $50.9 \%$ (27 cases) for tumors of the lower rectum (Table 2). The recurrence rate was $24.5 \%$ (13 cases) after abdominoperineal resection versus $67.9 \%$ (36 cases) after anterior resection of the rectum and $7.5 \%$ (4 cases) after local excision.

Table 3 describes the characteristics of recurrence. The most common symptom of recurrence was pelvic pain $(73.6 \%)$. The diagnosis of recurrence was made by abdominal CT scan in $47.1 \%$ of cases, with pelvic MRI in $13.2 \%$ and with endoscopy in $39.6 \%$ of cases. Locoregional recurrences were mainly located in the pelvis in $35.8 \%$, at the anastomotic site in $18.7 \%$, and both places in $13.2 \%$ cases. Distant metastases were located in the liver in $15.1 \%$ cases and the lung in $17.2 \%$ cases (Table 3).

Table 4 summarizes the univariate analysis of all the prognostic factors likely to affect the development of recurrence. The multivariate analysis (Table 5) revealed four independent parameters associated with the risk of recurrence after curative surgery: a distal margin $\leq 2 \mathrm{~cm}$ $(\mathrm{HR}=6.8,95 \%$ CI 2.7-16.6), extracapsular spread $(\mathrm{HR}=$ 4.4, 95\% CI 1.3-14), tumor stenosis ( $\mathrm{HR}=4.3,95 \% \mathrm{CI}$ $1.2-15.2)$, parietal invasion according to the TNM classification (HR $=3,95 \%$ CI 1-9.4).

Figure 2 illustrates the effect of these four prognostic factors on the recurrence-free survival rate. The mean recurrence-free survival was $59.7 \pm 7.53$ months for patients with the distal margin $\leq 2 \mathrm{~cm}$ versus $109.7 \pm 8.28$ months for those patients with the distal margin $>2 \mathrm{~cm}$. The presence of extracapsular spread reduced the mean recurrence-free survival from 95 months to 21 months. The non-stenotic nature of the tumor increased the mean recurrence-free survival from 48 months to 92 months. In those with parietal invasion, the mean recurrence-free survival was 92 months for $\mathrm{T} 1$ and $\mathrm{T} 2$
Table 1 Patient and tumor characteristics

\begin{tabular}{|c|c|}
\hline Characteristic & Number of patients $[n(\%)]$ \\
\hline Number of patients in this study & 188 \\
\hline Age (years) (mean) & 60.5 \\
\hline Sex ratio (M:F) & $1.35: 1$ \\
\hline \multicolumn{2}{|l|}{ Location of tumor } \\
\hline Upper rectum & $45(24)$ \\
\hline Middle rectum & $65(35)$ \\
\hline Lower rectum & $78(41)$ \\
\hline \multicolumn{2}{|l|}{ CT stage } \\
\hline $\mathrm{T} 1 / \mathrm{T} 2$ & $24(13)$ \\
\hline T3 & $155(82)$ \\
\hline T4 & $9(5)$ \\
\hline \multicolumn{2}{|l|}{ cN stage } \\
\hline NO & $82(44)$ \\
\hline $\mathrm{N}+$ & $106(56)$ \\
\hline \multicolumn{2}{|l|}{ cTNM stage } \\
\hline । & $49(27)$ \\
\hline$\|$ & $38(20)$ \\
\hline III & $98(51)$ \\
\hline IV & $3(2)$ \\
\hline \multicolumn{2}{|l|}{ Parietal invasion } \\
\hline PT1-T2 & $64(34)$ \\
\hline pT3-T4 & $124(66)$ \\
\hline \multicolumn{2}{|l|}{ pT stage } \\
\hline $\mathrm{T} 1$ & 14 \\
\hline $\mathrm{T} 2$ & 50 \\
\hline T3 & 107 \\
\hline T4 & 17 \\
\hline \multicolumn{2}{|l|}{ pN stage } \\
\hline No & 127 \\
\hline N1 & 34 \\
\hline N2 & 17 \\
\hline N3 & 10 \\
\hline \multicolumn{2}{|l|}{ PTNM stage } \\
\hline । & $56(30)$ \\
\hline$\|$ & $68(37)$ \\
\hline III & $61(32)$ \\
\hline IV & $3(1)$ \\
\hline Tumor perforation & $7(4)$ \\
\hline Invasion of surrounding organs & $16(8)$ \\
\hline \multicolumn{2}{|l|}{ Degree of differentiation } \\
\hline Well & $41(22)$ \\
\hline Moderate & $133(71)$ \\
\hline Poor & $13(7)$ \\
\hline Neoadjuvant therapy & $120(64)$ \\
\hline
\end{tabular}


Table 1 Patient and tumor characteristics (Continued)

\begin{tabular}{ll}
\hline Characteristic & Number of patients $[n(\%)]$ \\
\hline Type of surgery & $35(19)$ \\
Low anterior resection & $144(76)$ \\
Local excision & $9(5)$ \\
Laparoscopic surgery & $25(13)$ \\
Postoperative complications & $39(21)$ \\
Adjuvant therapy & $65(34)$ \\
Number of patients with recurrence & $53(28)$ \\
Median follow-up period & 57 months \\
Median recurrence-free survival & 54 months \\
Median survival after recurrence & 25 months \\
Median overall survival & 75 months \\
2-year overall survival & $73 \%$ \\
5-year overall survival & $54 \%$ \\
\hline
\end{tabular}

tumors whereas it was only 56 months for T3 and T4 tumors.

\section{Discussion}

Recurrence after curative surgery of the rectal adenocarcinoma is a serious health problem not only because of its high frequency but also because it considerably impacts of the life expectancy and the quality of life of the patients [1].
Several prognostic factors related to the patient, tumor, and therapeutic protocol (radio preoperative chemotherapy, surgical procedure, and adjuvant chemotherapy) affect the development of recurrence. Determination of these prognostic factors can help define high-risk patients who require more frequent postoperative surveillance and adjuvant therapy.

According to our study, the recurrence rate was estimated to be $44.6 \%$ at 5 years. The reported recurrence rate at 5 years is $25-37 \%$ which is slightly lower than that of this study $[17,18]$. A meta-analysis by Puhlman [19] reported the 5-year recurrence rate between $23 \%$ and $41 \%$ with a mean of $27 \%$.

Our results reflect the seriousness of the problem of recurrence after curative surgery of rectal adenocarcinoma in central Tunisia. Several factors could explain the increased risk of recurrence, particularly the disintegration of oncological and radiotherapy care services.

On multivariate analysis according to the Cox regression model, four prognostic factors for recurrence of rectal adenocarcinoma after curative surgery were identified: distal resection margin $\leq 2 \mathrm{~cm}(\mathrm{HR}=6.8,95 \%$ CI 2.7-16.6), extracapsular invasion $(\mathrm{HR}=4.4,95 \% \mathrm{CI} 1.3-14)$, tumor stenosis $(\mathrm{HR}=4.3,95 \% \mathrm{CI} 1.2-15.2)$, and degree of parietal invasion (T3/T4) $(\mathrm{HR}=3,95 \% \mathrm{CI} 1.1-9.4)$.

As with all the cancers, the level of resection must be at a maximum distance from the tumor to achieve at least 2 $\mathrm{cm}$ of macroscopic tumor-free resection margin during the surgical procedure. The macroscopic limit of a tumor

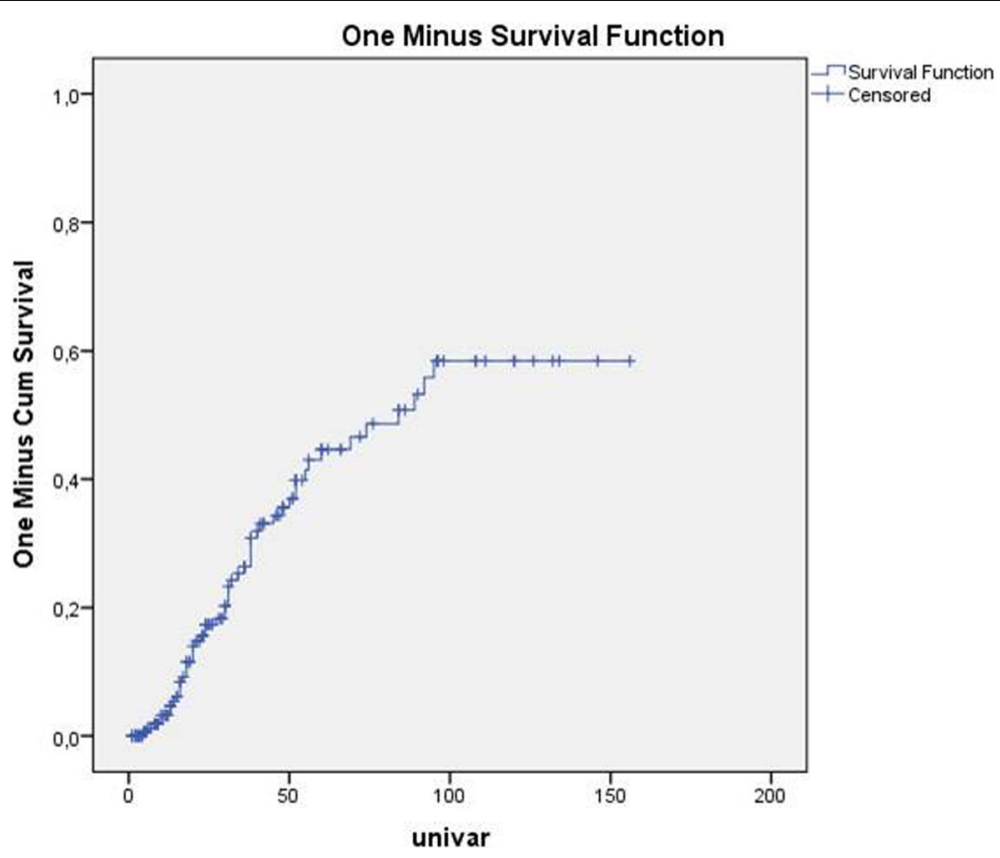

Fig. 1 predicting recurrence rate in function of time after curative resection for rectal adenocarcinoma 
Table 2 Demographic and clinical characteristics of the patients with and without recurrence

\begin{tabular}{|c|c|c|c|c|c|c|}
\hline & \multicolumn{2}{|c|}{ Without recurrence, $n=135$} & \multicolumn{2}{|c|}{ Recurrence, $n=53$} & \multicolumn{2}{|c|}{ Total, $N=188$} \\
\hline & $N$ & $\%$ & N & $\%$ & N & $\%$ \\
\hline \multicolumn{7}{|l|}{ Demographic characteristics } \\
\hline \multicolumn{7}{|l|}{ Sex } \\
\hline Male & 84 & 62.2 & 24 & 45.3 & 108 & 57.4 \\
\hline Female & 51 & 37.8 & 29 & 54.7 & 80 & 42.6 \\
\hline \multicolumn{7}{|c|}{ Age } \\
\hline$<50$ years & 23 & 17.0 & 18 & 34.0 & 41 & 21.8 \\
\hline$\leq 50$ years & 112 & 83.0 & 35 & 66.0 & 147 & 78.2 \\
\hline \multicolumn{7}{|l|}{ Clinical characteristics } \\
\hline \multicolumn{7}{|l|}{ Location of the tumor } \\
\hline Upper rectum & 36 & 26.7 & 9 & 17.0 & 45 & 23.9 \\
\hline Middle rectum & 49 & 36.3 & 16 & 30.2 & 65 & 34.6 \\
\hline Low rectum & 50 & 37.0 & 28 & 50.9 & 77 & 41.0 \\
\hline \multicolumn{7}{|c|}{ Size of the tumor } \\
\hline$<5 \mathrm{~cm}$ & 92 & 68.1 & 24 & 45.2 & 116 & 61.7 \\
\hline$>5 \mathrm{~cm}$ & 43 & 31.1 & 29 & 54.8 & 72 & 38,3 \\
\hline \multicolumn{7}{|l|}{ Stenotic character } \\
\hline Yes & 21 & 15 & 13 & 24.6 & 34 & 18 \\
\hline No & 114 & 85 & 40 & 75.4 & 154 & 82 \\
\hline \multicolumn{7}{|l|}{ CEA levels } \\
\hline Normal & 26 & 19.2 & 24 & 45.2 & 50 & 27 \\
\hline Abnormal & 109 & 80.8 & 29 & 54.8 & 138 & 73 \\
\hline \multicolumn{7}{|l|}{ Neoadjuvant therapy } \\
\hline Yes & 85 & 62.9 & 35 & 66 & 120 & 63.8 \\
\hline No & 50 & 37.1 & 18 & 34 & 68 & 36.2 \\
\hline \multicolumn{7}{|l|}{ Surgical intervention } \\
\hline Abdominoperineal resection & 22 & 15.6 & 13 & 24.5 & 35 & 18.1 \\
\hline Anterior resection of the rectum & 108 & 70.4 & 36 & 67.9 & 144 & 77.1 \\
\hline Local excision & 5 & 4.4 & 4 & 7.5 & 9 & 4.8 \\
\hline \multicolumn{7}{|l|}{ Distal margin } \\
\hline$\leq 2 \mathrm{~cm}$ & 37 & 27.4 & 31 & 58.4 & 68 & 37 \\
\hline$>2 \mathrm{~cm}$ & 90 & 72.6 & 22 & 41.6 & 112 & 63 \\
\hline \multicolumn{7}{|l|}{ Intraoperative incident } \\
\hline Yes & 32 & 23.7 & 17 & 32 & 49 & 26 \\
\hline No & 103 & 76.3 & 36 & 68 & 139 & 64 \\
\hline \multicolumn{7}{|l|}{ pT stage } \\
\hline $\mathrm{T} 1-\mathrm{T} 2$ & 54 & 40 & 10 & 18.8 & 64 & 34 \\
\hline T3-T4 & 81 & 60 & 43 & 81.2 & 124 & 66 \\
\hline \multicolumn{7}{|l|}{ Invasion of neighboring organs } \\
\hline Yes & 6 & 4 & 10 & 18.8 & 16 & 8.5 \\
\hline No & 129 & 96 & 43 & 81.2 & 172 & 11.5 \\
\hline \multicolumn{7}{|l|}{ Tumor perforation } \\
\hline Yes & 2 & 1.5 & 5 & 9.4 & 7 & 3.7 \\
\hline
\end{tabular}


Table 2 Demographic and clinical characteristics of the patients with and without recurrence (Continued)

\begin{tabular}{|c|c|c|c|c|c|c|}
\hline & \multicolumn{2}{|c|}{ Without recurrence, $n=135$} & \multicolumn{2}{|c|}{ Recurrence, $n=53$} & \multicolumn{2}{|c|}{ Total, $N=188$} \\
\hline & $N$ & $\%$ & $N$ & $\%$ & $N$ & $\%$ \\
\hline No & 133 & 98.5 & 48 & 90.6 & 181 & 96.3 \\
\hline \multicolumn{7}{|l|}{ pN stage } \\
\hline NO & 106 & 78.5 & 21 & 39.6 & 127 & 67.5 \\
\hline $\mathrm{N}+$ & 29 & 21.5 & 32 & 60.4 & 61 & 32.5 \\
\hline \multicolumn{7}{|c|}{ Extra capsular invasion } \\
\hline Yes & 8 & 6 & 31 & 58.4 & 39 & 20.7 \\
\hline No & 127 & 64 & 22 & 41.6 & 149 & 79.3 \\
\hline \multicolumn{7}{|c|}{ Vascular emboli } \\
\hline Yes & 10 & 7.4 & 20 & 37.7 & 30 & 16 \\
\hline No & 125 & 92.6 & 33 & 62.3 & 158 & 84 \\
\hline \multicolumn{7}{|c|}{$\begin{array}{l}\text { Lymphatic and perineural } \\
\text { invasion }\end{array}$} \\
\hline Yes & 7 & 5.2 & 14 & 26.4 & 21 & 11.1 \\
\hline No & 128 & 94.8 & 39 & 73.6 & 167 & 88.9 \\
\hline \multicolumn{7}{|l|}{ pTNM stage } \\
\hline | and || & 102 & 75.5 & 22 & 41.5 & 124 & 66 \\
\hline III and IV & 33 & 84.5 & 31 & 58.5 & 64 & 34 \\
\hline
\end{tabular}

Table 3 Characteristics of the recurrent disease

\begin{tabular}{|c|c|c|}
\hline & $n$ & $\%$ \\
\hline \multicolumn{3}{|l|}{ Presenting symptoms/signs } \\
\hline Pelvic pain & 39 & 73.6 \\
\hline $\begin{array}{l}\text { Alteration of the general } \\
\text { condition }\end{array}$ & 31 & 58.5 \\
\hline $\begin{array}{l}\text { Mass at digital rectal } \\
\text { examination }\end{array}$ & 20 & 37.7 \\
\hline \multicolumn{3}{|l|}{$\begin{array}{l}\text { Means of diagnosis of } \\
\text { recurrence }\end{array}$} \\
\hline $\begin{array}{l}\text { Abdominal and pelvic } \\
\text { CT scan }\end{array}$ & 25 & 47.1 \\
\hline Digestive endoscopy & 21 & 39,6 \\
\hline Pelvic MRI & 7 & 13.2 \\
\hline \multicolumn{3}{|l|}{ Recurrence location } \\
\hline \multicolumn{3}{|l|}{ Locoregional recurrence } \\
\hline Pelvic & 25 & 47.1 \\
\hline Anastomotic & 8 & 15.0 \\
\hline Pelvic and anastomotic & 10 & 18.8 \\
\hline \multicolumn{3}{|l|}{ Remote metastasis } \\
\hline Hepatic & 15 & 15.1 \\
\hline Pulmonary & 9 & 17.0 \\
\hline Bone & 3 & 5.6 \\
\hline Brain & 1 & 1.8 \\
\hline Ovarian & 1 & 1.8 \\
\hline
\end{tabular}

lesion is often exceeded at the microscopic level by submucosal tumor invasion. If the resection limit is microscopically invaded by the tumor, it will affect the long-term outcome as it will be a potential site for local recurrence. For tumors of the lower and middle rectum, studies have shown that there is no additional reduction in the risk of local recurrence with a distal margin greater than $2 \mathrm{~cm}$ below the lower end of the tumor [7-11].

Currently, a 1-cm distal margin has been suggested by several randomized studies, especially after neoadjuvant therapy $[11,12]$ to the safe limit [20]. Some studies [21, 22] compared oncology results between a distal resection margin $\leq 1 \mathrm{~cm}$ and $>1 \mathrm{~cm}$ and did not show a significant difference in terms of the recurrence rate. In our study, a distal resection margin $\leq 2$ $\mathrm{cm}$ was an independent predictor of recurrence on multivariate analysis.

The second important factor found in our study was extracapsular invasion which increased the risk of recurrence by fourfold. This would be explained by the fact that the lymph node, which is the first defense barrier of the body to prevent the lymphatic spread, does not control tumor invasion. Thus, the residual tumor cells lying outside the lymph nodes may become the site of tumor recurrence. Few studies have investigated extracapsular invasion in the analysis of risk factors for tumor recurrence. It has been studied in the cancers of other sites such as the vulva, lungs, and some digestive cancers such as the esophagus and stomach. In most of these studies, the 
Table 4 Univariate analysis to determine the factors associated with recurrence

\begin{tabular}{|c|c|c|c|c|c|}
\hline \multirow[t]{2}{*}{ Prognostic factors } & \multirow[t]{2}{*}{ Risk category } & \multirow{2}{*}{$\begin{array}{l}\text { Reference } \\
\text { category }\end{array}$} & \multicolumn{3}{|c|}{ Univariate analysis } \\
\hline & & & $\mathrm{HR}$ & $95 \% \mathrm{Cl}$ & $p$ \\
\hline \multicolumn{6}{|l|}{ Factors related to the population } \\
\hline Sex & Female & Male & 1.651 & $0.9-2.8$ & 0.07 \\
\hline Age & $<50$ years & $\geq 50$ years & 1.136 & $0.6-2.0$ & 0.66 \\
\hline \multicolumn{6}{|l|}{ Factors related to the tumor } \\
\hline Location & Low rectum & Upper or middle & 1.129 & $0.7-2.2$ & 0.35 \\
\hline Fixity & Mobile & Fixed & 1.084 & $0.5-2.0$ & 0.80 \\
\hline Stenotic character & Stenotic & Non-stenotic & 2.203 & $1.1-4.2$ & 0.01 \\
\hline Size & $\geq 5 \mathrm{~cm}$ & $<5 \mathrm{~cm}$ & 1.496 & $0.8-2.6$ & 0.15 \\
\hline \multicolumn{6}{|l|}{ Biologic factors } \\
\hline CEA levels & Abnormal & Normal & 0.721 & $0.3-1.3$ & 0.32 \\
\hline LDH levels > 400 & Present & Absent & 0.673 & $0.1-3.7$ & 0.65 \\
\hline \multicolumn{6}{|l|}{$\begin{array}{l}\text { Factors related to adjuvant } \\
\text { and neoadjuvant treatment }\end{array}$} \\
\hline Neoadjuvant radiotherapy & Absent & Present & 1.337 & $0.7-2.3$ & 0.31 \\
\hline Neoadjuvant radiochemotherapy & Absent & Present & 1.551 & $0.8-2.9$ & 0.17 \\
\hline Adjuvant chemotherapy & Absent & Present & 1.308 & $0.7-2.3$ & 0.37 \\
\hline \multicolumn{6}{|l|}{ Factors related to surgery } \\
\hline Urgency of the intervention & Yes & No & 7.027 & $0.9-52.6$ & 0.05 \\
\hline Experience of the surgeon & Junior & Senior & 0.888 & $0.3-1.9$ & 0.77 \\
\hline Surgical approach & Laparoscopic & Laparotomy & 0.962 & $0.3-2.7$ & 0.94 \\
\hline Surgical intervention & $\begin{array}{l}\text { Abdominoperineal } \\
\text { resection }\end{array}$ & $\begin{array}{l}\text { Anterior resection } \\
\text { of the rectum }\end{array}$ & 0.648 & $0.3-1.2$ & 0.18 \\
\hline Vascular ligation & $1 \mathrm{~cm}$ from the origin & At the origin & 1.334 & $0.7-2.3$ & 0.33 \\
\hline Distal margin & $\leq 2 \mathrm{~cm}$ & $>2 \mathrm{~cm}$ & 2.792 & $1.5-4.9$ & 0.00 \\
\hline Intraoperative incident & Yes & No & 3.716 & $1.6-8.4$ & 0.00 \\
\hline Anastomotic fistula & Present & Absent & 0.637 & $0.2-1.4$ & 0.63 \\
\hline \multicolumn{6}{|l|}{ Pathological factors } \\
\hline Parietal invasion ( $\mathrm{p} T$ stage) & $\mathrm{T} 3-\mathrm{T} 4$ & $\mathrm{~T} 1-\mathrm{T} 2$ & 2.278 & $1.1-4.5$ & 0.02 \\
\hline Invasion of neighboring organs & Yes & No & 3.040 & $1.5-6.0$ & 0.00 \\
\hline Tumor perforation & Yes & No & 4.128 & $1.6-10.5$ & 0.00 \\
\hline Ganglionic invasion (pN stage) & Yes & No & 2.677 & $1.5-4.6$ & 0.00 \\
\hline Extra capsular invasion & Yes & No & 2.789 & $1.1-6.6$ & 0.02 \\
\hline Vascular emboli & Yes & No & 3.817 & $2.1-6.6$ & 0.00 \\
\hline lymphatic and perineural invasion & Yes & No & 4.235 & $2.2-7.8$ & 0.00 \\
\hline Mucoid colloid component & Yes & No & 1.360 & $0.7-2.6$ & 0.34 \\
\hline pTNM stage & III and IV & | and || & 2.833 & $1.6-4.8$ & 0.00 \\
\hline
\end{tabular}

$H R$ hazard ratio, $\mathrm{Cl}$ confidence interval

extracapsular invasion was found to be a bad prognostic factor [10]. In colorectal cancer, because of the conflicting results in the reported studies, this parameter does not appear in TNM classification, nor standardized pathological reports [23]. A retrospective study carried out in Tunisia including 75 cases of colorectal adenocarcinoma concluded that the extracapsular invasion of lymph node metastasis correlated with the occurrence of local recurrences $(p=0.001)$ and metachronous metastases $(p=0.01)$. Our series confirms the prognostic value of extracapsular invasion in rectal adenocarcinoma.

The stenosing character of the tumor was identified in our study as a risk factor for the development of recurrence in rectal cancer. The tumor stenosis indicates that the disease process is going on for quite some time that 
Table 5 Multivariate analysis to identify the prognostic factors for recurrence in rectal adenocarcinoma

\begin{tabular}{|c|c|c|c|c|c|}
\hline \multirow[t]{2}{*}{ Prognostic factors } & \multirow[t]{2}{*}{ Risk category } & \multirow{2}{*}{$\begin{array}{l}\text { Reference } \\
\text { category }\end{array}$} & \multicolumn{3}{|c|}{$\underline{\text { Multivariate analysis }}$} \\
\hline & & & $\mathrm{HR}$ & $95 \% \mathrm{Cl}$ & $p$ \\
\hline \multicolumn{6}{|l|}{ Factors related to the population } \\
\hline Sex & Female & Male & 1.356 & $0.5-3.3$ & 0.50 \\
\hline Age & $<50$ years & $\geq 50$ years & 0.429 & $0.1-1.0$ & 0.07 \\
\hline \multicolumn{6}{|l|}{ Factors related to the tumor } \\
\hline Stenotic character & Stenotic & Non-stenotic & 4.387 & $1.2-15.2$ & 0.02 \\
\hline Size & $\geq 5 \mathrm{~cm}$ & $<5 \mathrm{~cm}$ & 0.710 & $0.2-1.7$ & 0.45 \\
\hline \multicolumn{6}{|l|}{$\begin{array}{l}\text { Factors related to adjuvant } \\
\text { and neoadjuvant treatment }\end{array}$} \\
\hline Neoadjuvant radiochemotherapy & Absent & Present & 1.502 & $0.6-3.3$ & 0.32 \\
\hline \multicolumn{6}{|l|}{ Factors related to surgery } \\
\hline Surgical intervention & $\begin{array}{l}\text { Abdominoperineal } \\
\text { resection }\end{array}$ & $\begin{array}{l}\text { Anterior resection } \\
\text { of the rectum }\end{array}$ & 1.216 & $0.4-3.1$ & 0.69 \\
\hline Distal margin & $\leq 2 \mathrm{~cm}$ & $>2 \mathrm{~cm}$ & 6.819 & $2.7-16.6$ & 0.00 \\
\hline Intraoperative incident & Yes & No & 1.627 & $0.2-9.0$ & 0.57 \\
\hline \multicolumn{6}{|l|}{ Pathological factors } \\
\hline Parietal invasion (pT stage) & $\mathrm{T} 3-\mathrm{T} 4$ & $\mathrm{~T} 1-\mathrm{T} 2$ & 3.073 & $1.1-9.4$ & 0.05 \\
\hline Perforated character of the tumor & Yes & No & 2.279 & $0.1-33.6$ & 0.54 \\
\hline Ganglionic invasion (pN stage) & Yes & No & 0.300 & $0-6.7$ & 0.44 \\
\hline Extra capsular invasion & Yes & No & 4.408 & $1.3-14.0$ & 0.01 \\
\hline Vascular emboli & Yes & No & 1.398 & $0.5-3.4$ & 0.47 \\
\hline lymphatic and perineural invasion & Yes & No & 2.369 & $0.7-7.0$ & 0.12 \\
\hline pTNM stage & III and IV & I and || & 4.623 & $0.2-90.9$ & 0.31 \\
\hline
\end{tabular}

$H R$ hazard ratio, $\mathrm{Cl}$ confidence interval

exposes the patient to the risk of tumor dissemination and may explain the increased risk for locoregional and distant recurrence. In a study by Larsen et al. [24] including 254 patients with T3 and T4 rectum cancers, the stenosing character of the tumor was associated with a higher rate of recurrence $(p=0.005)$ and a lower survival rate $(p=0.005)(0.01)$. In another study by Chapet et al. [25], the stenosing character of the tumor was not an independent prognostic factor for recurrence, but the 5 -year survival rate was reduced to $12 \%$. In our series, the stenosing character of the tumor was significantly associated with the risk of recurrence, thus concordant with the results of Larsen et al. [24].

Another important prognostic factor for recurrence found in this study was the degree of parietal infiltration. The vascular channels are present in the third layer of the rectal wall which corresponds to T3 of parietal infiltration according to the TNM classification. Any invasion of the rectal wall beyond this stage is associated with vascular invasion and therefore with a higher risk of dissemination and recurrence. The degree of parietal invasion was one of the five known prognostic factors for rectal cancer which were identified at a North American consensus conference [26].
Besides, several studies have shown that the degree of parietal invasion was significantly associated with the risk of recurrence $[27,28]$. A recent study by Chen et al. involving 359 patients operated for rectal cancer showed that the T3 stage has a higher risk of recurrence compared to the T2 stage $(p=0.012)$ [3]. Our study confirms that the degree of parietal invasion is an independent predictor of recurrence.

In the literature, other prognostic factors for recurrence have been noted but not found significant in this study. These factors are related to the quality of the surgical procedure [29-31] such as total mesorectal excision, neoadjuvant treatment [32, 33], preoperative radiochemotherapy, and histopathological criteria of the tumor such as the number of lymph nodes involved, the perineural invasion, and the vascular emboli [34].

The knowledge of the prognostic factors for recurrence of rectal adenocarcinoma after curative surgery could calculate a predictive risk score. This score will define a profile of patients at very high risk of recurrence who need a surveillance protocol that differs from the recommended guidelines.

This study is limited by its retrospective nature. However, the medical records specific to the tumor pathologies were very well preserved (operating records, radiological, 


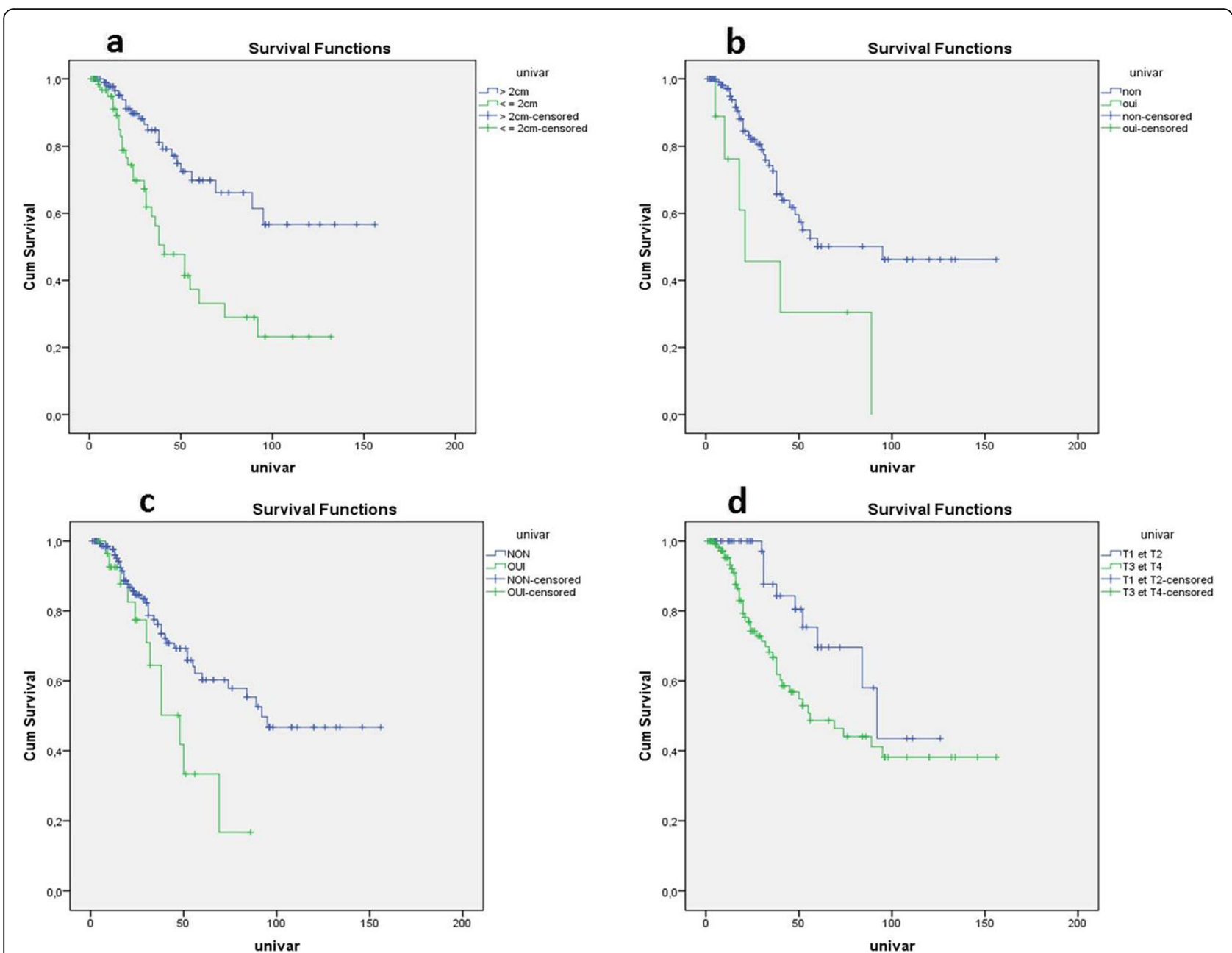

Fig. 2 Kaplan-Meier curves comparing the recurrence-free survival of the patients according to the four parameters independently associated with the risk of recurrence after curative surgery. a Distal margin (log-rank $=<10^{-3}$ ). b Extracapsular invasion of lymph node metastasis (logrank $=0.015)$. $\mathbf{c}$ Tumor stenosis (log-rank= 0.016). $\mathbf{d}$ Parietal invasion according to the TNM classification (log-rank=0.016)

pathological, and other details); thus, the risk of information bias attributed to the loss of records is less and does not affect the reliability of the results.

\section{Conclusion}

This study revealed distal resection margin $\leq 2 \mathrm{~cm}$, extracapsular invasion of lymph node metastasis, tumor stenosis, and degree of parietal invasion $\geq \mathrm{T} 3$ to be independent prognostic factors for recurrence of rectal adenocarcinoma in African patients. Future multicentric national scale studies are required to validate the results of this study.

This study was approved by the Sahloul Hospital ethical committee. All procedures performed in studies involving human participants were in accordance with the ethical standards of the institutional and/or national research committee (include name of committee + reference number) and with the 1964 Helsinki declaration and its later amendments or comparable ethical standards.

\section{Acknowledgements}

The authors gratefully acknowledge all of the investigators for their contributions to the trial.

\section{Article guarantor}

Houssem Ammar

\section{Authors' contributions}

WF, MbL, SL contributed to the data collection and editing of the manuscript. MA contributed to the editing of the manuscript and the supervision of the manuscript. AM contributed to reviewing the article before submission not only for spelling and grammar but also for its intellectual content; constructing an idea or hypothesis for research; and organizing and supervising the course of the article. HA and RG contributed to the editing of the manuscript, literature review, and drafting the manuscript. MK contributed to reviewing the article before submission not only for spelling and grammar but also for its intellectual content; taking responsibility in execution of the experiments, patient follow-up, data management; and organizing and supervising the course of the project or the article. MBM and ABA contributed to the manuscript correction and supervision of the manuscript. All authors read and approved the final manuscript. 


\section{Funding}

There is no funding for this study.

\section{Availability of data and materials}

Access to the data and the calculation method can be obtained from the authors by email (hosshoss24@hotmail.fr).

\section{Compliance with ethical standards}

This retrospective study was reviewed and approved by the Ethics Committee of Sahloul hospital.

\section{Ethics approval and consent to participate}

All procedures performed in studies involving human participants were in accordance with the ethical standards of the institutional and/or national research committee of Sahloul Hospital. Written informed consent was obtained from all patients enrolled in the investigation. The study protocol conformed to the guidelines of the regional ethical committee of Sahloul Hospital.

\section{Competing interests}

The authors declare that they have no competing interests.

\section{Author details}

${ }^{1}$ Department of Gastrointestinal Surgery, Sahloul Hospital, Sousse, Tunisia. ${ }^{2}$ Department of Anesthesia and Intensive Care, Sahloul Hospital, Sousse, Tunisia. ${ }^{3}$ Department of Gastrointestinal Surgery, Synergy Institute of Medical Sciences, Dehradun, India.

Received: 18 July 2019 Accepted: 3 October 2019

Published online: 28 October 2019

\section{References}

1. Hsu T-W, Wei C-K, Yin W-Y, et al. Prognostic factors affecting shortterm outcome of curative rectal cancer resection. Tzu Chi Med J. 2013;25(1):47-50

2. Manfredi S, Benhamiche AM, Meny B, et al. Population-based study of factors influencing occurrence and prognosis of local recurrence after surgery for rectal cancer. Br J Surg. 2001;88(9):1221-7.

3. Chen W, Chen M, Liao Z, et al. Lymphatic vessel density as predictive marker for the local recurrence of rectal cancer. Dis Colon Rectum. 2009; 52(3):513-9.

4. Ceyhan GO, Liebl F, Maak M, et al. The severity of neural invasion is a crucial prognostic factor in rectal cancer independent of neoadjuvant radiochemotherapy. Ann Surg. 2010;252(5):797-804.

5. Engstrom PF, Arnoletti JP, Benson AB 3rd, et al. NCCN clinical practice guidelines in oncology: colon cancer. J Natl Compr Canc Netw. 2009;7(8): 778-831.

6. Labianca R, Nordlinger B, Beretta GD, et al. Primary colon cancer: ESMO Clinical Practice Guidelines for diagnosis, adjuvant treatment and follow-up. Ann Oncol. 2010;21:v70-7.

7. Pollett WG, Nicholls RJ. The relationship between the extent of distal clearance and survival and local recurrence rates after curative anterio resection for carcinoma of the rectum. Ann Surg. 1983;198(2):159-63.

8. Poritz LS, Sehgal $R$, Hartnett $K$, et al. Tumor volume and percent positive lymph nodes as a predictor of 5-year survival in colorectal cancer. Surgery. 2011;150(4):649-55.

9. Saha S, Shaik M, Johnston $G$, et al. Tumor size predicts long-term survival in colon cancer: an analysis of the National Cancer Data Base. Am J Surg. 2015; 209(3):570-4.

10. Heald RJ, Husband E, Ryall R. The mesorectum in rectal cancer surgery-the clue to pelvic recurrence? Br J Surg. 1982;69(10):613-6.

11. Paty PB, Enker WE, Cohen AM, et al. Treatment of rectal cancer by low anterior resection with coloanal anastomosis. Ann Surg. 1994;219(4):365.

12. Vernava AM 3rd, Moran M, Rothenberger DA. A prospective evaluation of distal margins in carcinoma of the rectum. Surg Gynecol Obstet. 1992; 175(4):333-6.

13. Arya $S$, Das $D$, Engineer $R$, et al. Imaging in rectal cancer with emphasis on local staging with MRI. Indian J Radiol Imaging. 2015;25(2):148-61.

14. Yang YJ, Cao L, Li ZW, et al. Fluorouracil-based neoadjuvant chemoradiotherapy with or without oxaliplatin for treatment of locally advanced rectal cancer: an updated systematic review and meta-analysis. Oncotarget. 2016:7(29):45513-24

15. Garrer WY, El Hossieny HA, Gad ZS, et al. Appropriate timing of surgery after neoadjuvant chemoradiation therapy for locally advanced rectal cancer. Asian Pac J Cancer Prev. 2016;17(9):4381-9.

16. Sun Z, Adam MA, Kim J, et al. Optimal timing of surgery after neoadjuvant chemoradiotherapy for locally advanced rectal cancer. J Am Coll Surg. 2016; 222(4):367-74.

17. Bosset JF, Maingnon P. Chimioradiothérapie adjuvante des cancers du rectum. Cancer/Radiothérapie. 1998;2(6):703-7.

18. Melville A, Sheldon TA, Gray R, et al. Follow-up of patients with colorectal cancer. A métanalys. Am Surg. 1994;219:174-82.

19. Pahlman L. Radiochemotherapy as an adjuvant treatment for rectal cancer. Recent Results Cancer Res. 1998;146:141-51.

20. Gérard JP, André T, Bibeau F, et al. Rectal cancer: French intergroup clinical practice guidelines for diagnosis, treatments and follow-up (SNFGE, FFCD, GERCOR, UNICANCER, SFCD, SFED, SFRO). Dig Liver Dis. 2017:49(4):359-67.

21. Nash GM, Weiss A, Dasgupta $R$, et al. Close distal margin and rectal cancer recurrence after sphincter-preserving rectal resection. Dis Colon Rectum. 2010:53(10):1365-73.

22. Leo E, Belli F, Miceli $\mathrm{R}$, et al. Distal clearance margin of $1 \mathrm{~cm}$ or less: a safe distance in lower rectum cancer surgery. Int J Color Dis. 2009:24(3):317.

23. Bibeau F, Goldman-Levy G. Cancer colorectal: compte rendu anatomopathologique type en 2014. Oncologie. 2014;16(11-12):525-36.

24. Larsen SG, Wiig JN, Dueland S, et al. Prognostic factors after preoperative irradiation and surgery for locally advanced rectal cancer. Eur J Surg Oncol. 2008:34(4):410-7.

25. Chapet $\mathrm{O}$, Romestaing $\mathrm{P}$, Mornex $\mathrm{F}$, et al. Preoperative radiotherapy for rectal adenocarcinoma: which are strong prognostic factors? Int J Radiat Oncol Biol Phys. 2005;61(5):1371-7.

26. Alline $M$, Martin MB, Pierre EC, Anne $M$, et al. De l'oesophage au rectum: les facteurs pronostiques ganglionnaires et chirurgicaux. Bull Cancer. 2014; 101(4):368-72.

27. Hida K, Okamura R, Park SY, et al. A new prediction model for local recurrence after curative rectal cancer surgery: development and validation as an Asian collaborative study. Dis of Colon Rectum. 2017;60(11):1168-74.

28. Tokodai $\mathrm{K}$, Narimatsu $\mathrm{H}$, Nishida $\mathrm{A}$, et al. Risk factors for recurrence in stage II/III colorectal cancer patients treated with curative surgery: the impact of postoperative tumor markers and an infiltrative growth pattern. J Surg Oncol. 2016;114(3):368-74.

29. Peng J-Y, Li Z-N, Wang Y. Risk factors for local recurrence following neoadjuvant chemoradiotherapy for rectal cancers. World J Gastroenterol. 2013;19(32):5227.

30. Arbman G, Nilsson E, Hallböök $O$, et al. Local recurrence following total mesorectal excision for rectal cancer. Br J Surg. 1996;83(3):375-9.

31. Wibe A, Møller B, Norstein J, et al. A national strategic change in treatment policy for rectal cancer-implementation of total mesorectal excision as routine treatment in Norway. A national audit. Dis Colon Rectum. 2002; 45(7):857-66.

32. Bosset J-F, Laurence C, Gilles C, et al. Chemotherapy with preoperative radiotherapy in rectal cancer. N Engl J Med. 2006;355(11):1114-23.

33. Gérard JP, Conroy T, Bonnetain F, et al. Preoperative radiotherapy with or without concurrent fluorouracil and leucovorin in T3-4 rectal cancers: results of FFCD 9203. J Clin Oncol. 2006;24(28):4620-5.

34. Enker WE, Thaler HT, Cranor ML, et al. Total mesorectal excision in the operative treatment of carcinoma of the rectum. J Am Coll Surg. 1995; 181(4):335-46.

\section{Publisher's Note}

Springer Nature remains neutral with regard to jurisdictional claims in published maps and institutional affiliations. 